

\section{Sumário}

Crimes de Responsabilidade do Presidente da República.............................................. 2 Carlos Ayres Britto

Perda de mandato parlamentar por força de condenaÇão criminal na jurisprudênCia

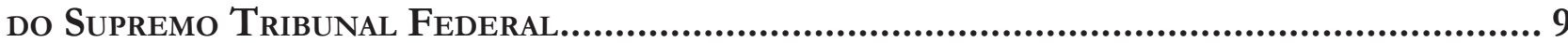
José Levi Mello do Amaral Júnior

Poder NORMATIVO DAS CORTES CONSTITUCIONAIS: O CASO BRASILEIRO.....................................16 Inocêncio Mártires Coelho

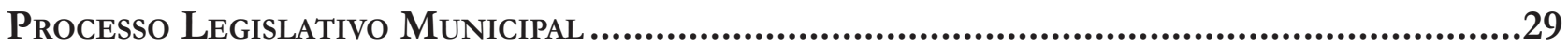
José Levi Mello do Amaral Júnior

Primeiras linhas Sobre a OPÇÃo POlítico-Criminal da Deserção Militar: A NECESSÁRIA contribuição das Políticas Públicas ..............................................................................42

Antonio Henrique Graciano Suxberger e Danilo Gustavo Vieira Martins

IMPLICAÇÕES DO DIREITO AO VOTO AOS IMIGRANTES: AMEAÇA À SOBERANIA NACIONAL OU EFETIVAÇÃO DE UM DIREITO FUNDAMENTAL?

Juliana Cleto

Crimen, Desempleo y Actividad Económica en Chile

Sergio Zuñiga-Jara, Sofía Ruiz Campo e Karla Soria-Barreto

O IMPACTO DE DIFERENTES TIPOS DE REPRESSÃO LEGAL SOBRE AS TAXAS DE HOMICÍDIO ENTRE OS ESTADOS BRASILEIROS 100

Adolfo Sachsida, Mário Jorge Cardoso de Mendonça e Tito Belchior Silva Moreira

Análise dos impactos diretos e indiretos do Programa de P\&D da ANEEL no setor

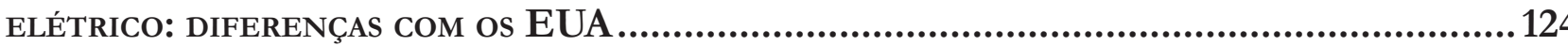
Igor Polezi Munhz, Alessandra Cristina Santos Akkari e Neusa Maria Bastos Fernandes dos Santos

Shango Unchained? State In(Capacity), Urban Bias, and the Power Africa Initiative 146 Tom Brower

LEVANDO O ORÇAMENTO A SÉRIO COMO INSTRUMENTO DE CONTROLE DE POLÍTICAS PÚBLICAS179 Andre Bogossian 
ESTIMATIVA DE DEMANDA PELA FORMALIZAÇÃO DA ECONOMIA INFORMAL NO AGRESTE PERNAMBUCANO: UMA APLICAÇ̃̃o DO MÉTODO DE VALORAÇÃO CONTINGENTE...............................200 Monaliza de Oliveira Ferreira e Kelly Samá Lopes de Vasconcelos

Implicações do Programa Nacional de Alimentação Escolar (PNAE) na renda e orGANIZAÇÃO DE AGRICULTORES FAMILIARES.

Nádia Kunkel Sziwelski, Carla Rosane Paz Arruda Teo, Luciara de Souza Gallina, Fabiula Grahl e Cimara Filippi

Desenvolvimento das famílias E A POBREZA no NORDESTE do BrasiL Nadja Simone Menezes Nery de Oliveira, Solange de Cassia Inforzato de Souza e Aricieri Devidé Junior

EfEITos Colaterais dA MiNERAÇÃo No MEIO AMBIENTE

Márcio Oliveira Portella

ParticipaÇão Popular E ACESSo À INFORMaÇão AMbiental PARa PRESERVAÇÃo do MEIO AMBIENTE ECOLOGICAMENTE EQUILIBRADO 278 Luciano Marcos Paes

Políticas Públicas Para A FormaÇão E AVAliaÇão de Magistrados: A CONTRIbUiÇão da EDUCAÇÃo JUDICIAL ATRAVÉS DAS ESCOLAS DE MAGISTRATURA. 289

Flávio José Moreira Gonçalves

\section{Resenhas}

Simpler: THE FUture of Government, de CAss Sustein 316

Veyzon Campos Muniz 


\title{
Participação popular e acesso à informação ambiental para preservação do meio ambiente ecologicamente equilibrado*
}

\section{Popular participation and access to environmental information to ecologically balanced environment preservation}

Luciano Marcos Paes**

\section{Resumo}

A partir da Constituição Federal Brasileira de 1988, são colocados à disposição da população mecanismos de participação para que se possa exercer a cidadania e, assim, fortalecer o regime democrático por meio da participação popular, inclusive, nas questões que envolvam a proteção e a preservação do meio ambiente. No presente artigo, pretende-se, por meio de revisão bibliográfica, realizar breve análise da possibilidade e da necessidade de participação do cidadão, por meio do acesso à informação ambiental, em relação à preservação do meio ambiente ecologicamente equilibrado.

Palavras-chave: Participação popular. Acesso à informação. Meio ambiente.

\begin{abstract}
Since Brazilian Federal Constitution of 1998 mechanisms for participation are made available to population so that the citizenship can be exercised and than the democratic regime gain strength through popular participation including questions that envolve the environment protection and preservation. In the present study intends, through a bibliographic review, to perform a brief analysis of the possibility and the need for citizen participation, by accessing to environment information, in the ecologically balanced environment preservation.
\end{abstract}

Keywords: Popular participation. Access to information. Environment.

* Recebido em 20/09/2015 Aprovado em 15/11/2015

** Possui graduação em Direito pela Universidade de Caxias do Sul - UCS (2014). Mestrando em Direito pela Universidade de Caxias do Sul__UCS (2015). E-mail: lmpaes@ucs.br

\section{SUMÁRIO}

1 Introdução. 2 Participação popular e acesso à informação ambiental. 3 Preservação do meio ambiente ecologicamente equilibrado. 4 Considerações finais. 5 Referências. 


\section{INTRODUÇÃO}

É dever dos órgãos e entidades públicas incentivar a divulgação de informações de interesse coletivo ou geral por eles produzidas. O artigo 19 da Declaração Universal dos Direitos Humanos, o artigo 19 do Pacto Internacional sobre Direitos Civis e Políticos, o artigo 13 da Convenção Interamericana sobre Direitos Humanos, o artigo 9 da Carta Africana sobre Direitos Humanos e dos Povos e o artigo 10 da Convenção Europeia sobre Direitos Humanos reconhecem o acesso às informações públicas como direito humano fundamental, pois a vida democrática em sociedade é marcada por um elemento essencial: a necessidade de o indivíduo fazer escolhas, ou seja, "a informação serve para o processo de educação de cada pessoa e da comunidade, mas a informação visa também dar a chance à pessoa informada de tomar posição ou pronunciar-se sobre a matéria informada ${ }^{1}$ ".

Igualmente, a Convenção de Aarhus de 1998 é um dos mais importantes instrumentos do Direito Internacional do Ambiente, pois traz a ideia de que o desenvolvimento sustentável só poderá ser alcançado por meio do envolvimento de todas as partes interessadas, ou melhor, todos os cidadãos passam a ser detentores do direito de acesso à informação relativa ao meio ambiente; do direito de participação nos procedimentos de tomada de decisão em matérias ambientais e do direito de acesso à justiça nessas matérias. ${ }^{2}$

$\mathrm{O}$ acesso à informação, além de ser um direito de qualquer indivíduo, também é um direito difuso pertencente a toda a coletividade eis que o acesso amplo às informações públicas resulta em ganhos para a comunidade de maneira geral ${ }^{3}$.

Durante o regime militar, no Brasil, dos anos 1964 até 1985, o direito de acesso às informações públicas foi um dos direitos formal ou informalmente suspensos.

A Constituição Federal de 1988, em seu artigo 1º, parágrafo único, refere expressamente que "todo o poder emana do povo, que o exerce por meio de representantes eleitos ou diretamente, nos termos desta Constituição" e, assim, o Estado Democrático de Direito traz consigo a ideia de cidadania como princípio fundamental.

Com a promulgação da Constituição Federal Brasileira de 1988, são colocados à disposição da população mecanismos de participação para que se possa exercer a cidadania e, assim, fortalecer o regime democrático por meio da participação popular, inclusive, nas questões que envolvam a proteção e a preservação do meio ambiente.

Uma das melhores maneiras de tratar essas questões é assegurar a participação dos cidadãos e disponibilizar informações com o objetivo de preservação ambiental, seja na esfera administrativa, legislativa ou judicial, uma vez que "a pluralidade de sujeitos que se utiliza do meio ambiente é capaz de trazer argumentos, opiniões e soluções mais eficientes para sua proteção, pois quem vive o problema tem uma visão diferente do que quem está de fora"»".

Este texto construído com base em revisão bibliográfica tem como objetivo, sem a pretensão de esgotar o assunto, analisar e fomentar a possibilidade de participação do cidadão, por meio do acesso à informação e da necessidade de utilização dessas informações para auxiliar nas ações que visem à proteção e à preservação do meio ambiente ecologicamente equilibrado.

1 MACHADO, Paulo Afonso Leme. Direito ambiental brasileiro. 21. ed. São Paulo: Malheiros, 2013. p. 123.

2 LANCEIRO, Rui Tavares. O direito de acesso à informação ambiental em Portugal: alguns problemas. In: CONFERÊNCIA DO INSTITUTO DE CIÊNCIAS JURÍDICO-POLÍTICAS, 2014, Lisboa. A trilogia de Aarbus: os direitos à informação, à participação e à justiça ambiental. Lisboa: Faculdade de Direito Universidade de Lisboa, 2015. p. 29-61. p. 30-31.

3 AGÊNCIA DE NOTÍCIAS DOS DIREITOS DA INFÂNCIA. Acesso à informação e controle social das politicas públicas. Brasília: ANDI, 2009. Disponível em: <http://www.fesmedia-latin america.org/uploads/media/Acceso_a_informacao.pdf>. Acesso em: 05 ago. 2015.

4 SOUZA, Leonardo da Rocha de. Direito ambiental e democracia deliberativa. Jundiaí: Paco, 2013. p. 112. 


\section{ParticipaçÃo POPULAR E ACESSO À INFORMAÇÃo Ambiental}

A Constituição Federal Brasileira no artigo 5, inciso XIV, prevê que "é assegurado a todos o acesso à informação e resguardado o sigilo da fonte, quando necessário ao exercício profissional" 5 bem como refere ainda, no inciso XXXIII, que os cidadãos "têm direito de receber dos órgãos públicos informações de seu interesse particular, ou de interesse coletivo ou geral"'.

De outro lado, a participação popular caracteriza-se pela luta na conquista de espaços para aumentar a participação social, ou seja, é um dos aspectos mais desafiadores sobre os quais se posta a democracia participativa uma vez que

não se pode pensar na preservação, conservação e gestão da qualidade ambiental fora de um regime de democracia participativa, em que se garanta às pessoas em geral - individualmente, reunidas em grupos ou representadas por entes habilitados - a possibilidade de tomar parte nas instâncias de decisão relacionadas à matéria e de exercer o controle sobre as atividades e omissões públicas e privadas potencial ou efetivamente lesivas. ${ }^{7}$

A participação popular surge como elemento que traz mecanismos que buscam renovar e dar maior oportunidade à democratização da sociedade e, em contrapartida, o acesso à informação é uma precondição para a participação do cidadão e dos grupos organizados da sociedade afim de servir aos interesses mais amplos da coletividade.

De fato,

a participação popular transforma-se no referencial de ampliação de possibilidades de acesso dos setores populares dentro de uma perspectiva de desenvolvimento da sociedade civil e de fortalecimento dos mecanismos democráticos, mas também para garantir a execução eficiente de programas de compensação social no contexto das políticas de ajuste estrutural e de deliberação da economia e privatização do patrimônio do Estado. ${ }^{8}$

A participação popular visando à preservação e à proteção do meio ambiente insere-se num quadro mais amplo da participação diante dos interesses difusos e coletivos da sociedade, o que faz um desafio maior ensejar participação pois o termo participar significa que a opinião de uma pessoa pode ser levada em conta. ${ }^{9}$

Como bem refere Machado10 “quem estiver mal informado nem por isso estará impedido de participar, mas a qualidade de sua participação será prejudicada. A ignorância gera apatia ou inércia dos que teriam legitimidade para participar".

Igualmente no âmbito internacional, a Convenção de Aarhus busca garantir o acesso do público à informação em matéria de ambiente, sem que se tenha que provar interesse na questão, além de fomentar deveres de recolha e difusão de informação em matéria de ambiente (art. $4^{\circ}$ e $5^{\circ}$ da Convenção de Aarhus). ${ }^{11}$

É indiscutível a importância do direito de acesso à informação nos estados democráticos modernos como uma forma de o cidadão entender o funcionamento do Estado e participar da execução e fiscalização de suas políticas públicas.

5 BRASIL. Constituição (1988). Constituição da República Federativa do Brasil. Disponível em: < http://www.planalto.gov.br/ccivil_03/constituicao/ConstituicaoCompilado.htm>. Acesso em: 10 dez. 2015.

6 BRASIL. Constituição (1988). Constituição da República Federativa do Brasil. Disponível em: <http://www.planalto.gov.br/ccivil_03/constituicao/ConstituicaoCompilado.htm>. Acesso em: 10 dez. 2015.

7 MIRRA, Álvaro Luiz Valery. Participação, processo civil e defesa do meio ambiente no direito brasileiro. 2010. 346 f. Tese (Doutorado) Faculdade de Direito da Universidade de São Paulo, São Paulo, 2010. p. 60.

8 JACOBI, Pedro Roberto. Espaços públicos e práticas participativas na gestão do meio ambiente no Brasil. Sociedade e Estado, Brasília, v. 18, n. 1-2, p. 315-338, jan./dez. 2003. p. 317.

9 MACHADO, Paulo Afonso Leme. Direito ambiental brasileiro. 21. ed. São Paulo: Malheiros, 2013. p. 126.

10 MACHADO, Paulo Afonso Leme. Direito à informação e meio ambiente. São Paulo: Malheiros, 2006. p. 34.

11 LANCEIRO, Rui Tavares. O direito de acesso à informação ambiental em Portugal: alguns problemas. In: CONFERÊNCIA DO INSTITUTO DE CIÊNCIAS JURÍDICO-POLÍTICAS, 2014, Lisboa. A trilogia de Aarbus: os direitos à informação, à participação e à justiça ambiental. Lisboa: Faculdade de Direito Universidade de Lisboa, 2015. p. 29-61. p. 31. 
Nessa mesma esteira, a Lei de Acesso à Informação - Lei 12.527/11 traduz as condições para o acesso às informações governamentais no Brasil, desde que essas condições possam ser incorporadas a uma política pública capaz de assegurar e instrumentalizar o exercício desses direitos, bem como a proteção à destruição e manipulação indevidas dessas informações.

É dever dos órgãos e entidades públicas incentivar, independentemente de requerimentos, a divulgação em local de fácil acesso, informações de interesse coletivo ou geral produzidas ou mantidas por eles.

No entanto, o direito de acesso à informação tem outra característica importante que é a de instrumento ou ferramenta de trabalho para a realização de outros direitos, visto que, só munidos de informações relevantes, as organizações e os indivíduos podem exigir os mais diversos direitos pois a informação permite o monitoramento e a participação.

Quando se trata de matéria ambiental além da proteção dada pela Constituição de 1988 e das garantias asseguradas pela Lei Geral de Acesso à Informação - Lei 12.527/11 importante referir, também, a Lei 10.650/03 que dispõe sobre o acesso público aos dados e informações existentes nos órgãos e entidades integrantes do SISNAMA (Sistema Nacional do Meio Ambiente) por meio de contato com os diferentes órgãos ambientais do Estado (federal, estadual ou municipal), assegurando a possibilidade de acesso à informação ambiental de forma genérica.

São exemplos de informação ambiental os relatórios sobre atuação de agências ambientais, instruções normativas, resoluções, relatórios de impacto ao meio ambiente, atas, outros documentos de reuniões de órgãos ambientais etc.

Todos os órgãos ligados ao SISNAMA têm o prazo de trinta dias, a partir da data do pedido, para entregar as informações solicitadas, todavia, a definição de tal prazo foi superada pela edição da Lei Geral de Acesso à Informação ao dispor em seu artigo 11 que o órgão ou entidade pública deverá autorizar ou conceder o acesso imediato à informação disponível e, não sendo possível conceder de imediato, o órgão ou entidade que receber o pedido deverá conceder a informação no prazo de vinte dias prorrogáveis por mais dez, mediante justificativa expressa, da qual será cientificado o requerente.

Ainda, a Lei 10.650/03 também estabelece que informações sobre temas relacionados à questão ambiental ${ }^{12}$ devem ser disponibilizas à população obrigatoriamente e independente de requisição.

São características da informação ambiental: (a) a tecnicidade da informação ambiental; (b) a compreensibilidade da informação ambiental; (c) a tempestividade da informação ambiental; (d) a imprescindibilidade da informação ambiental em situação de emergência e, (e) a prestação da informação independe de interesse pessoal do informado. ${ }^{13}$

Por outro lado, a Administração Pública não é o único canal para a obtenção da informação ambiental já que a informação se torna pública não porque está em poder do Poder Público, mas porque sua natureza é de interesse público ou social, assim, mesmo estando em mãos de pessoas ou das empresas privadas, havendo esse tipo de interesse na informação, ela se torna de natureza pública. ${ }^{14}$

12 Lei 10.650/03 - Art. 2: Os órgãos e entidades da Administração Pública, direta, indireta e fundacional, integrantes do Sisnama, ficam obrigados a permitir o acesso público aos documentos, expedientes e processos administrativos que tratem de matéria ambiental e a fornecer todas as informações ambientais que estejam sob sua guarda, em meio escrito, visual, sonoro ou eletrônico, especialmente as relativas a: I - qualidade do meio ambiente; II - políticas, planos e programas potencialmente causadores de impacto ambiental; III - resultados de monitoramento e auditoria nos sistemas de controle de poluição e de atividades potencialmente poluidoras, bem como de planos e ações de recuperação de áreas degradadas; IV - acidentes, situações de risco ou de emergência ambientais; V - emissões de efluentes líquidos e gasosos, e produção de resíduos sólidos; VI - substâncias tóxicas e perigosas; VII diversidade biológica; VIII - organismos geneticamente modificados. BRASIL. Lei ñ 10.650, de 16 de abril de 2003. Dispõe sobre o acesso público aos dados e informações nos órgãos e entidades integrantes do Sisnama. Disponível em: <http://www.planalto.gov. br/ccivil_03/Leis/2003/L10.650.htm>. Acesso em: 10 dez. 2015.

13 MACHADO, Paulo Afonso Leme. Direito à informação e meio ambiente. São Paulo: Malheiros, 2006. p. 91-95

14 MACHADO, Paulo Afonso Leme. Direito à informação e meio ambiente. São Paulo: Malheiros, 2006. p. 104-105. 
Ademais,

a informação ambiental não tem o fim exclusivo de formar a opinião pública [...] o grande destinatário da informação - o povo, em todos os seus segmentos, incluindo o científico não governamental - tem o que dizer e opinar ${ }^{15}$.

Segundo a resenha apresentada por Michel Delnoy, ligeiramente adaptada por Álavo Mirra, neste artigo, a participação pública em matéria ambiental tem como finalidades:

(a) suprir as insuficiências estruturais ou conjunturais da democracia representativa, permitindo aos cidadãos recuperar sua parcela de poder de controle sobre os destinos da sociedade, com a instituição de um regime de democracia participativa;

(b) melhorar a qualidade das decisões públicas, a partir das informações obtidas pelas autoridades junto à sociedade e das intervenções de indivíduos e grupos nos processos decisórios;

(c) aumentar a efetividade das decisões públicas, pelo apoio recebido da população que delas participou;

(d) reforçar o espaço do exercício do direito de todos à proteção do meio ambiente, como contrapartida ao alargamento do campo de atuação técnico-burocrática do Poder Público e ao desenvolvimento mal controlado das atividades privadas degradadoras;

(e) permitir aos cidadãos em geral cumprir seu dever de proteger o meio ambiente;

(f) favorecer a tomada de consciência por parte do setor privado a respeito das consequências ambientais das decisões que ele próprio toma. ${ }^{16}$

Aliás, um dos desafios que contém a democracia é a implementação de iniciativas para permitir o acesso da população a informações públicas, acolher espaços de participação que podem e devem ser criados, efetivados e alargados, com base nos valores democráticos e participativos que fundamentam a Constituição Federal Brasileira, fomentando, assim, a participação cidadã que pode tanto assumir a forma de contribuição nos debates como de intervenção propriamente dita nos processos decisórios, seja em âmbito administrativo, seja no judicial. ${ }^{17}$

\section{Preservação do meio ambiente ecologicamente gQuilibrado}

A atual Constituição Federal Brasileira traz o meio ambiente como bem jurídico constitucional integrando assim a categoria daqueles valores fundamentais da nossa sociedade, pois, com a proteção do meio ambiente, salvaguardamos não só a vida nas suas várias dimensões (individual, coletiva e até das gerações futuras), mas as próprias bases da vida. ${ }^{18}$

Com efeito tal objetivo exige:

pleno exercício da cidadania participativa e dos mecanismos da democracia. E é nesse sentido que o texto constitucional impõe inúmeros instrumentos de efetivação da ordem constitucional ambiental, ampliando a participação popular, por meios administrativos e judiciais, exigindo educação ambiental, amplitude e transparência de informações e de acesso à justiça, bem como inúmeros deveres de gestão ambiental aos poderes públicos, pois a solidariedade é pressuposto para a conquista da sustentabilidade ambiental. ${ }^{19}$

15 MACHADO, Paulo Afonso Leme. Direito ambiental brasileiro. 21. ed. São Paulo: Malheiros, 2013. p. 125.

16 MIRRA, Álvaro Luiz Valery. Participação, processo civil e defesa do meio ambiente no direito brasileiro. 2010. 346 f. Tese (Doutorado) Faculdade de Direito da Universidade de São Paulo, São Paulo, 2010. p. 62.

17 SILVEIRA, Clóvis Eduardo Malinverni. Risco ecológico abusivo: a tutela do patrimônio ambiental nos processos coletivos em face do risco socialmente intolerável. Caxias do Sul: Educs, 2014. p. 264.

18 ROTHENBURG, Walter Cláudios. A constituição ecológica. In: KISHI, Sandra Akemi Shimada; SILVA, Solange Teles da; SOARES, Inês Virgínia Prado (Org.). Desafios do direito ambiental no século XXI. São Paulo: Malheiros, 2005. p. 813-831. p. 814-815.

19 PADILHA, Norma Sueli. Fundamentos constitucionais do direito ambiental brasileiro. São Paulo: Elsevier, 2010. p. 160. 
A partir da inclusão do tema "meio ambiente" na Constituição Federal de 1988, transformações começaram e, assim, não somente se afirmou o direito a um meio ambiente sadio ou equilibrado como foram sendo inseridos instrumentos jurídicos para sua manutenção. ${ }^{20}$

No direito ambiental brasileiro, o artigo 225 da Constituição Federal de 1988 estabelece uma série de deveres direcionados à efetivação da participação, tais como o dever de cooperação entre estado e sociedade (art. 225, caput), o dever de educação ambiental (art. 225, $\int 1^{\circ}$, inc. VI) e o dever de publicidade dos estudos prévios de impacto ambiental (art. 225, $₫ 1^{\circ}$, inc. IV).

Certamente, é necessário entender a dinâmica entre as legislações que estabelecem direitos sociais e as políticas públicas que buscam garantir esses direitos, de modo que muitas das políticas públicas desenhadas pelo texto constitucional permanecem apenas como um conjunto de intenções.

Participar significa que a opinião de uma pessoa pode ser levada em conta e "portanto, permite que interessados proponham formas de prevenção das agressões ambientais e participem dessa prevenção" 21 .

É um desafio permanente ensejar participação e, nesse contexto, vários documentos internacionais reconhecem o direito à informação, dentre os quais podemos citar a Declaração do Rio de Janeiro, da Conferência das Nações Unidas para o Meio Ambiente e o Desenvolvimento de 1992, em seu princípio 10 que diz:

a melhor maneira de tratar as questões ambientais é assegurar a participação, no nível apropriado, de todos os cidadãos interessados. No nível nacional, cada indivíduo terá acesso adequado às informações relativas ao meio ambiente de que disponham as autoridades públicas, inclusive informações acerca de materiais e atividades perigosas em suas comunidades, bem como a oportunidade de participar dos processos decisórios. Os Estados irão facilitar e estimular a conscientização e a participação popular, colocando as informações à disposição de todos. Será proporcionado o acesso efetivo a mecanismos judiciais e administrativos, inclusive no que se refere à compensação e reparação de danos.

A Convenção de Aarhus ${ }^{22}$ também refere o acesso à informação como um dos pilares para a promoção do envolvimento dos cidadãos nas questões ambientais bem como para a aplicação da legislação ambiental, consagrando, assim, os posicionamentos legislativos de muitos países e colocando a saúde humana, os sítios culturais e as construções como objeto de consideração quando esses bens forem vulnerados, ou puderem ser lesados. ${ }^{23}$

Nesse sentido, é reflexo a importância da informação ambiental na forma como é cultuada pelo direito luso, especialmente ao tratar dos princípios do direito do ambiente, ao mencionar que

o princípio (e o correlativo direito) de participação está fortemente ligado a um outro direito que em geral vem sendo reconhecido em termos cada vez mais amplos aos cidadãos: o direito à informação. Só quando os cidadãos estão devidamente informados é que podem ter oportunidade de exercer convenientemente o seu direito de participação.

Com reflexo da importância que a informação - também enquanto pressuposto indeclinável de uma participação responsável e efectiva - assume em matéria ambiental [...] garantir o direito de acesso à informação sobre o ambiente detida pelas autoridades públicas, assegurar que a informação sobre

20 MACHADO, Paulo Afonso Leme. Direito à informação e meio ambiente. São Paulo: Malheiros, 2006. p. 88.

21 SOUZA, Leonardo da Rocha de. Direito ambiental e democracia deliberativa. Jundiaí: Paco, 2013. p. 115.

22 No Artigo $2^{\circ}$, item 3 da Convenção de Aarhus está dito que: entende-se por «informação em matéria de ambiente» qualquer informação disponível sob forma escrita, visual, oral, electrónica ou de qualquer outra forma sobre: a) O estado dos elementos do ambiente, tais como o ar e a atmosfera, a água, o solo, a terra, a paisagem e os sítios naturais, a diversidade biológica e as suas componentes, incluindo, genericamente, organismos modificados e a interação entre estes elementos; b) Fatores, tais como substâncias, energia, ruído e radiação, e atividades ou medidas, incluindo medidas administrativas, acordos, políticas, legislação, planos e programas em matéria de ambiente que afetem ou possam afetar os elementos do ambiente, no âmbito do acima mencionado subparágrafo a), e custo-benefício e outros pressupostos e análises económicas utilizados no processo de tomada de decisão em matéria de ambiente. ORGANIZAÇÃO DAS NAÇÕES UNIDAS. Resolução da Assembleia da República n 11/2003. Convenção sobre Acesso à Informação, Participação do Público no Processo de Tomada de Decisão e Acesso à Justiça em Matéria de Ambiente. Disponível em: <http://www.gddc.pt/siii/docs/rar11-2003.pdf>. Acesso em: 20 jul. 2015.

23 MACHADO, Paulo Afonso Leme. Direito à informação e meio ambiente. São Paulo: Malheiros, 2006. p. 79. 
ambiente seja divulgada e disponibilizada ao público e promover o acesso à informação através da utilização de tecnologias telemáticas ou electrónicas, responsabilizando as autoridades públicas por uma série de medidas necessárias para assegurar a informação ambiental e garantindo aos cidadãos o direito de acesso à informação sobre ambiente, independente do seu interesse na matéria. ${ }^{24}$

Portanto, as sujeições às obrigações de prestação de informação ambiental estão vinculadas quer pelo direito internacional como pelo direito pátrio de forma muito abrangente, sem que se tenha que provar ter um interesse específico na questão para obtenção de informações em matéria de ambiente.

Além disso, a definição de informação em matéria de ambiente engloba conteúdos informativos sob qualquer forma, sobre o estado do ambiente, sobre os fatores e medidas destinados a sua proteção, inclusive as análises de custos/benefícios econômicos e sobre a segurança das pessoas, as condições de vida, os locais de interesse cultural e as construções, na medida em que possam afetar o meio ambiente por um desses fatores ou atividades. ${ }^{25}$

Todavia um ponto de maior conflitualidade coloca-se na delimitação das situações em que é admissível o indeferimento do pedido de informação sem caracterizar recusa abusiva de prestação de informações especialmente quando há uma relação triangular composta pelo direito de obtenção da informação, interesse púbico e o interesse privado econômico, cuja a atividade é potencialmente agressora de determinados bens ambientais. ${ }^{26}$

A obtenção da informação não é por si só causa de atraso de um determinado projeto da inciativa econômica privada, porém poderá ocorrer situação diferente quando a informação pretendida colidir com a confidencialidade inerente ao segredo comercial ou industrial ou com a confidencialidade de dados pessoais sem o consentimento dos terceiros afetados.

$\mathrm{O}$ acesso à informação "nesse plano, atua como mecanismo de equalização das relações jurídicas, possibilitando ao cidadão (ou associação civil) titular do direito ao ambiente de, em um patamar mais igualitário, reivindicar o respeito ao seu direito fundamental ao ambiente ${ }^{27}$ ", pois o direito de acesso à informação possui uma dupla dimensão:

subjetiva, na medida em que a informação e o acesso às suas fontes são essenciais para que o cidadão compreenda o fundamento e o limite dos seus direitos em face dos poderes públicos; objetiva, porquanto o controle da transparência da decisão administrativa depende da possibilidade de os cidadãos se informarem e serem informados sobre os passos do iter procedimental. ${ }^{28}$

Igualmente, ao levamos em conta a preservação do meio ambiente,

formar uma consciência ambiental ética é a alternativa mais viável para garantir a perpetuação da vida num planeta vitimado por tantas agressões. A tutela da qualidade do meio ambiente é uma questão que não pode figurar em segundo plano, por que, por meio dela, o bem protegido é a vida como um valor maior da existência do ser. Em face disso, em que pese a questão do acesso à informação ter seu caráter utópico, mostra-se evidente a sua importância, inclusive para a compreensão sistêmica das questões ambientais atuais. Sua dinamização e disseminação por meio de um processo educativo mais amplo e dentro da cultura política existente apontam para a garantia da supremacia do direito coletivo sobre o individual. ${ }^{29}$

24 DIAS, José Eduardo Figueiredo. Direito constitucional e administrativo do ambiente. 2. ed. Coimbra: Almedina, 2007. p. 24.

25 LANCEIRO, Rui Tavares. O direito de acesso à informação ambiental em Portugal: alguns problemas. In: CONFERÊNCIA DO INSTITUTO DE CIÊNCIAS JURÍDICO-POLÍTICAS, 2014, Lisboa. A trilogia de Aarbus: os direitos à informação, à participação e à justiça ambiental. Lisboa: Faculdade de Direito Universidade de Lisboa, 2015. p. 29-61. p. 42.

26 MARQUES, Francisco Paes. A convecção de Aarhus e as relações jurídicas multipolares. . In: CONFERÊNCIA DO INSTITUTO DE CIÊNCIAS JURÍDICO-POLÍTICAS, 2014, Lisboa. A trilogia de Aarbus: os direitos à informação, à participação e à justiça ambiental. Lisboa: Faculdade de Direito Universidade de Lisboa, 2015. p. 61-75. p. 61.

27 FENSTERSEIFER, Tiago. Direitos fundamentais e proteção do ambiente: a dimensão ecológica da dignidade humana no marco jurídico constitucional do estado socioambiental de direito. Porto Alegre: Livraria do Advogado, 2008. p. 127.

28 PORTUGAL. Tribunal Constitucional. Acordão n. 136. Segunda Secção. Relator: Conselheiro Paulo Mota Pinto. Lisboa, 15 de março de 2005. A caminho de uma ecocidadania: notas sobre o direito à informação ambiental. Disponível em: <http://www. tribunalconstitucional.pt/tc/acordaos/20050136.html>. Acesso em: 20 jul. 2015.

29 BARROS, Lucivaldo Vasconcelos. O Estado (in)transparente: limites do direito à informação socioambiental do Brasil. 2008. 368 f. Tese (Doutorado) - Centro de Desenvolvimento Sustentável, Universidade de Brasília, Brasília, 2008. p. 340. 
Assim, o acesso à informação não só representa inversão na lógica de segredo tradicionalmente associada ao funcionamento da máquina administrativa, como e, sobretudo, acresce legitimidade da decisão por força da potencial abertura a um contraditório público, pois a partilha do "poder" que está associada à posse da informação representa um estágio de evolução superior do Estado Democrático de Direito provando que há democracia para além do sufrágio ${ }^{30}$.

Os estados democráticos têm a obrigação de implementar sistemas legais para facilitar o acesso à informações, pois o direito de ter acesso ao seu passado e a conhecer o seu presente aumenta as noções de cidadania, a boa governança, a eficiência da administração pública, a fiscalização, o combate à corrupção, o desenvolvimento humano, a inclusão social bem como o êxito de outros direitos socioeconômicos, civis e políticos $^{31}$.

\section{Considerações finais}

Parece indiscutível que tão importante quanto a norma legal é a necessidade de uma política pública que operacionalize o direito de acesso à informação, pois é por meio da qualidade e da quantidade de informação que irá se traduzir a intensidade da participação na vida social e política. ${ }^{32}$

A informação é uma ferramenta de controle democrático e, nesse sentido, o direito à informação está intimamente ligado ao conceito de democracia participativa e respeito aos direitos fundamentais de proteção do ambiente consistentemente equilibrado.

De fato a obtenção da informação ambiental mostra-se necessária e adequada à defesa do ambiente, porém a possibilidade de obtenção da informação não é por si só garantia de preservação, ademais quando em jogo outros interesses de ordem econômica.

O direito de acesso à informação, à participação e o acesso à justiça em sede ambiental (Trilogia de Aarhus) no sentido de incrementar a transparência na tomada de decisões com a possibilidade de seu controle não obsta contudo a análise judicial da questão.

Se a democracia participativa depende do nível de informação dos cidadãos (e da capacidade de aprender e analisar criticamente), o acesso à informação e a sustentabilidade ambiental têm íntima ligação, uma vez que a informação não é algo neutro que deva ser trabalhado, apenas, como um mero dado ou registro e, sim, a informação trabalhada em sua dimensão política pode auxiliar nos processos decisórios, especialmente aqueles em que o interesse coletivo difuso é predominante.

Partilhar a proteção ambiental por meio de um esforço solidário entre entidades públicas e privadas é um dever que reverte em favor de todos os membros da comunidade, existentes e futuros, e o direito de acesso à informação provoca um magnetismo especial sobre a tutela ambiental, gerando e alimentando um sentimento de responsabilidade partilhada. ${ }^{33}$

Por certo "cabe fomentar a invenção de novas formas democrático-participativas - não como panaceia,

30 PORTUGAL. Tribunal Constitucional. Acordão n. 136. Segunda Secção. Relator: Conselheiro Paulo Mota Pinto. Lisboa, 15 de março de 2005. A caminho de uma ecocidadania: notas sobre o direito à informação ambiental. p. 62. Disponível em: <http://www. tribunalconstitucional.pt/tc/acordaos/20050136.html>. Acesso em: 20 jul. 2015.

31 AGÊNCIA DE NOTÍCIAS DOS DIREITOS DA INFÂNCIA. Acesso à informação e controle social das políticas públicas. Brasília: ANDI, 2009. Disponível em: <http://www.fesmedia-latin america.org/uploads/media/Acceso_a_informacao.pdf>. Acesso em: 05 ago. 2015.

32 MACHADO, Paulo Afonso Leme. Direito à informação e meio ambiente. São Paulo: Malheiros, 2006. p. 34.

33 PORTUGAL. Tribunal Constitucional. Acordão n. 136. Segunda Secção. Relator: Conselheiro Paulo Mota Pinto. Lisboa, 15 de março de 2005. A caminho de uma ecocidadania: notas sobre o direito à informação ambiental. p. 63. Disponível em: <http://www. tribunalconstitucional.pt/tc/acordaos/20050136.html>. Acesso em: 20 jul. 2015. 
mas como desafio e como exigência histórica a povos que pretendem ser democráticos" ${ }^{34}$, uma vez que o debate público bem informado permite que o cidadão conheça e participe dos processos decisórios e monitore as ações do governo fazendo uso das informações públicas ambientais em ações específicas, utilizando dados oficiais para formulação de ações de monitoramento e defesa do meio ambiente ecologicamente equilibrado, possibilitando, assim, a conciliação de interesses privados divergentes e o adequado balanceamento do risco ambiental a ser assumido por toda coletividade, uma vez que "num primeiro momento foi dada a oportunidade ao homem para dominar, controlar e dispor de todas as coisas oferecidas pela natureza e agora ele descobre que deve voltar a sua atenção para controlar e dominar as suas próprias ações ${ }^{35}$ ".

\section{REFERÊNCIAS}

AGÊNCIA DE NOTÍCIAS DOS DIREITOS DA INFÂNCIA. Acesso à informação e controle social das políticas públicas. Brasília: ANDI, 2009. Disponível em: <http://www.fesmedia-latin america.org/uploads/media/ Acceso_a_informacao.pdf>. Acesso em: 05 ago. 2015.

BARROS, Lucivaldo Vasconcelos. O Estado (in)transparente: limites do direito à informação socioambiental do Brasil. 2008. 368 f. Tese (Doutorado) - Centro de Desenvolvimento Sustentável, Universidade de Brasília, Brasília, 2008.

BRASIL. Constituição (1988). Constituição da República Federativa do Brasil. Disponível em: <http://www.planalto.gov.br/ccivil_03/constituicao/ConstituicaoCompilado.htm>. Acesso em: 10 dez. 2015.

BRASIL. Decreto ñ 592, de 6 de julho de 1992. Atos Internacionais. Pacto Internacional sobre Direitos Civis e Políticos. Promulgação. Disponível em: <http://www.planalto.gov.br/ccivil_03/decreto/1990-1994/ D0592.htm>. Acesso em: 10 dez. 2015.

BRASIL. Lei $n^{\circ}$ 10.650, de 16 de abril de 2003. Dispõe sobre o acesso público aos dados e informações nos órgãos e entidades integrantes do Sisnama. Disponível em: < http://www.planalto.gov.br/ccivil_03/ Leis/2003/L10.650.htm>. Acesso em: 10 dez. 2015.

BRASIL. Lei $n^{\circ} 12.527$, de 18 de novembro de 2011. Regula o acesso a informações previsto no inciso XXXIII do art. $5^{\circ}$, no inciso II do $\int 3^{\circ}$ do art. 37 e no $\int 2^{\circ}$ do art. 216 da Constituição Federal; altera a Lei no 8.112, de 11 de dezembro de 1990; revoga a Lei $n^{\circ}$ 11.111, de 5 de maio de 2005, e dispositivos da Lei $\mathrm{n}^{\circ}$ 8.159, de 8 de janeiro de 1991; e dá outras providências. Disponível em: <http://www.planalto.gov.br/ccivil_03/_ ato2011-2014/2011/lei/112527.htm>. Acesso em: 10 dez. 2015.

CONSELHO DA EUROPA. Convenção Europeia sobre Direitos Humanos. Disponível em: < http://www.gddc. $\mathrm{pt} /$ direitos-humanos/textos-internacionais-dh/tidhregionais/conv-tratados-04-11-950-ets-5.html>. Acesso em: 05 ago. 2015.

CONVENÇÃO INTERAMERICANA SOBRE DIREIOTS HUMANOS. Pacto de San José da Costa Rica. Disponível em: <http://www.pge.sp.gov.br/centrodeestudos/bibliotecavirtual/instrumentos/sanjose. htm>. Acesso em: 05 ago. 2015.

DIAS, José Eduardo Figueiredo. Direito constitucional e administrativo do ambiente. 2. ed. Coimbra: Almedina, 2007.

FENSTERSEIFER, Tiago. Direitos Fundamentais e proteção do ambiente: a dimensão ecológica da dignidade

34 SILVEIRA, Clóvis Eduardo Malinverni. Risco ecológico abusivo: a tutela do patrimônio ambiental nos processos coletivos em face do risco socialmente intolerável. Caxias do Sul: Educs, 2014. p. 265.

35 BARROS, Lucivaldo Vasconcelos. O Estado (in)transparente: limites do direito à informação socioambiental do Brasil. 2008. 368 f. Tese (Doutorado) - Centro de Desenvolvimento Sustentável, Universidade de Brasília, Brasília, 2008. p. 341. 
humana no marco jurídico constitucional do estado socioambiental de direito. Porto Alegre: Livraria do Advogado, 2008.

JACOBI, Pedro Roberto. Espaços públicos e práticas participativas na gestão do meio ambiente no Brasil. Sociedade e Estado, Brasília, v. 18, n. 1-2, p. 315-338, jan./dez. 2003.

LANCEIRO, Rui Tavares. O direito de acesso à informação ambiental em Portugal: alguns problemas. In: CONFERÊNCIA DO INSTITUTO DE CIÊNCIAS JURÍDICO-POLÍTICAS, 2014, Lisboa. $A$ trilogia de Aarbus: os direitos à informação, à participação e à justiça ambiental. Lisboa: Faculdade de Direito Universidade de Lisboa, 2015. p. 29-61.

MACHADO, Paulo Afonso Leme. Direito à informação e meio ambiente. São Paulo: Malheiros, 2006.

MACHADO, Paulo Afonso Leme. Direito ambiental brasileiro. 21. ed. São Paulo: Malheiros, 2013.

MARQUES, Francisco Paes. A convecção de Aarhus e as relações jurídicas multipolares. . In: CONFERÊNCIA DO INSTITUTO DE CIÊNCIAS JURÍDICO-POLÍTICAS, 2014, Lisboa. A trilogia de Aarbus: os direitos à informação, à participação e à justiça ambiental. Lisboa: Faculdade de Direito Universidade de Lisboa, 2015. p. 61-75.

MIRRA, Álvaro Luiz Valery. Participação, processo civil e defesa do meio ambiente no direito brasileiro. 2010. 346 f. Tese (Doutorado) - Faculdade de Direito da Universidade de São Paulo, São Paulo, 2010.

ORGANIZAÇÃO DAS NAÇÕES UNIDAS. Resolução da Assembleia da República ñ 11/2003. Convenção sobre Acesso à Informação, Participação do Público no Processo de Tomada de Decisão e Acesso à Justiça em Matéria de Ambiente. Disponível em: <http://www.gddc.pt/siii/docs/rar11-2003.pdf>. Acesso em: 20 jul. 2015.

ORGANIZAÇÃO DAS NAÇÕES UNIDAS. Declaração do rio sobre meio ambiente e desenvolvimento. Disponível em: <http://www.onu.org.br/rio20/img/2012/01/rio92.pdf>. Acesso em: 20 jul. 2015.

ORGANIZAÇÃO DAS NAÇÕES UNIDAS. Declaração Universal dos Direitos Humanos. Disponível em: <http://www.ohchr.org/EN/UDHR/Documents/UDHR_Translations/por.pdf>. Acesso em: 05 ago. 2015.

PADILHA, Norma Sueli. Fundamentos constitucionais do direito ambiental brasileiro. São Paulo: Elsevier, 2010.

PORTUGAL. Tribunal Constitucional. Acordão n. 136. Segunda Secção. Relator: Conselheiro Paulo Mota Pinto. Lisboa, 15 de março de 2005. A caminho de uma ecocidadania: notas sobre o direito à informação ambiental. Disponível em: <http://www.tribunalconstitucional.pt/tc/acordaos/20050136.html>. Acesso em: 20 jul. 2015.

ROTHENBURG, Walter Cláudios. A constituição ecológica. In: KISHI, Sandra Akemi Shimada; SILVA, Solange Teles da; SOARES, Inês Virgínia Prado (Org.). Desafios do direito ambiental no século XXI. São Paulo: Malheiros, 2005. p. 813-831.

SILVEIRA, Clóvis Eduardo Malinverni. Risco ecológico abusivo: a tutela do patrimônio ambiental nos processos coletivos em face do risco socialmente intolerável. Caxias do Sul: Educs, 2014.

SISTEMA AFRICANO DE PROTEÇÃO DOS DIREITOS HUMANOS. Carta Africana sobre Direitos Humanos e dos Povos. Disponível em: < http://www.gddc.pt/direitos-humanos/textos-internacionais-dh/tidhregionais/carta-africa.html>. Acesso em: 05 ago. 2015.

SOUZA, Leonardo da Rocha de. Direito ambiental e democracia deliberativa. Jundiaí: Paco, 2013.

UNIVERSIDADE DE CAXIAS DO SUL. Guia para elaboração de trabalhos acadêmicos. 3. ed. Caxias do Sul: UCS, 2015. Disponível em: <https://www.ucs.br/site/midia/arquivos/guia_2015.pdf>. Acesso em: 10 dez. 2015. 
Para publicar na revista Brasileira de Políticas Públicas, acesse o endereço eletrônico www.rbpp.uniceub.br

Observe as normas de publicação, para facilitar e agilizar o trabalho de edição. 